\title{
N-Acetyl cysteine for prevention of contrast induced nephropathy
}

\author{
Anisul Awal1 ${ }^{1}$, Syed Ali Hasan ${ }^{1}$, Md. Abu Siddique ${ }^{1}$, Bikash Subedi1 ${ }^{1}$ Jahanara Arzu${ }^{1}$ Quazi Arif Ahmed ${ }^{1}$, \\ KMHS Sirajul Haque ${ }^{1}$, Md. Ashraf Uddin Sultan ${ }^{1}$, Neena Islam ${ }^{1}$ \\ ${ }^{1}$ Department of Cardiology Bangabandhu sheikh mujib Medical University (BSMMU), Shahbag, Dhaka \\ Address for Correspondence \\ Dr. Anisul Awal, Department of Cardiology, Bangabandhu Sheikh Mujib Medical University \\ Shahbag, Dhaka \\ E-mail : anisulawal@yahoo.com
}

\begin{abstract}
The antioxidant $\mathrm{N}$-acetyl Cysteine prevents contrast induced nephropathy in patients with impaired renal function who undergo coronary angiogeaphy. However its role in Bangladeshi population is not clear. This study was done determine whether oral acetylcysteine prevents contrast induced nephropathy in high risk patients. 100 patients with mild to moderate renal insufficiency who are undergoing elective coronary angiography with or without intervention.50 patients were randomy assigned to receive oral $\mathrm{N}$ acetyl cysteine $(600 \mathrm{mg})$ twice daily on the day before and on the day of procedure. All patients received low osmolar contrast agent.10 (20\%) control patients (no premedicationgroup) and none of acetyl cysteine $(0 \%)$ group developed a more than $25 \%$ increase in serum creatinine level within 48 hours after contrast exposure. Acetyl cysteine prevents contrast induced nephropathy.
\end{abstract}

Keywords : Anti Oxident, contrast induced nephropathy.

\section{Introduction}

Contrast induced nephropathy is a recognized complication after coronary angiography and intervention that has been associated with prolonged hospitalization and adverse clinical outcomes ${ }^{1-3}$. It is reported that $14.5 \%$ of patients develop contrast induced nephropathy $(\mathrm{CIN})^{2}$. This problem assumes greater and greater importance with increased use of invasive radiological procedures to diagnose and treat coronary artery disease.

CIN is potentially preventable because the administration of radio contrast agent is predictable and high risk population has also been identified ${ }^{4}$. Patients at greater risk are those with impaired renal function ${ }^{5}$, particularly that caused by diabetic nephropathy ${ }^{6}$, However other than the use of intravenous hydration and lower osmolarity contrast media, no previous strategies has been shown to prevent CIN.

$\mathrm{N}$ acetyl cysteine ia an anti oxidant that has been shown to attenuate ischemic renal failure in animal studies ${ }^{7}$. The low cost of acetyl cysteoine, its ease of administration and its limited adverse effects are all compelling reasons to further investigate its role in patients undergoing coronary angiography.

\section{Methods}

This study was carried out in the department of Cardiology of Bangabandhu Sheikh Mujib Medical University from January 2007 to December 2008. This study protocol was approved by ethical committee of the department of cardiology. Patients undergoing coronary angiography with or without intervention with mild to moderate renal impairment were randomly selected for the study and those having history of contrast allergy, patients on renal dialysis, advanced congestive cardiac failure, patients unwilling to undergo the procedures were excluded from the study.

Total of 100 patients were selected and divided into two groups -Group A as control group and group B with patients receiving $\mathrm{N}$-acetylcysteine and hydration as premedication.

Preprocedural serum creatinine was considered as basal serum creatinine. Basal serum creatinine ${ }^{3} 1.2 \mathrm{mg} / \mathrm{dl}$ was considered as mild renal impairment as different study show $\mathrm{S}$ creatinine ${ }^{3} 1.2 \mathrm{mg} / \mathrm{dl}$ is equivalent to creatinine clearance rate of $£ 60 \mathrm{ml} / \mathrm{min}$ which indicate mild renal impairment, main risk factor for CIN. After taking brief history, preliminary selection was done and the purpose of the study was explained in details to each subject. Informed consent obtained from the subject. They were advised to take usual daily diet, to do normal physical activities and to avoid drugs that significantly interfere with serum creatinine level (NSAID, Metformin). Patients were assigned as

a) Group A patients who admitted in the morning of the undergoing procedure who could not get premedication.

b) Group B patients who were given N-acetylcystine 
$600 \mathrm{mg}$ orally in bid dose for two days, starting a day before the procedure in high risk group patient before CAG / PCI along with prehydration with $1 \mathrm{ml} / \mathrm{kg}$ /hour normal saline intravenously 12 hours before and 12 hours after the CAG and PCI in high risk patients.

Serum creatinine was estimated 24 hours after the contrast exposure in the same laboratory from where basal serum creatinine estimated.

Creatinine clearance $(\mathrm{CrCl})$ rate was calculated from Cockcroft-Gault formula.

\section{Statistical analysis}

Statistical analysis was conducted on SPSS (Statistical Pakckage for Social Science) software for windows version 12.0. Categorical data were expressed in percentage or number.Parametric data were expressed in mean $\pm \mathrm{SD}$. Parametric data were evaluated by Student's " $t$ " test and categorical data were evaluated by chi-square test as needed Significance was defined as $\mathrm{p}$ value $<0.05$.

\section{Results}

A total of 100 admitted coronary heart disease patients under went coronary angiography (CAG) and percutaneous coronary intervention selected for this study. The age group ranges from 32-76 years. The baseline variables including diabetes, hypertension, dyslipidemia, BMI, ejection fraction, angiographic diagnosis and amount of dye used were similar in both group.

TableI Baseline characteristics

\begin{tabular}{|c|c|c|c|}
\hline Charaeteristics & $\begin{array}{l}\text { Croup A } \\
(n-50) \\
\text { Na. (\%) }\end{array}$ & $\begin{array}{l}\text { Graup B } \\
(n-50) \\
\text { No. (n/) }\end{array}$ & P value \\
\hline 1.Age & $52(32-80)$ & $58(38-76)$ & 0.032 \\
\hline \multicolumn{4}{|l|}{$2 \mathrm{sex}:$} \\
\hline Male & $44(3896)$ & $42(8496)$ & 0.55 \\
\hline Fumak & $6(12 \%)$ & $8(1696)$ & \\
\hline 3.BMI & $25.16+3.65$ & $24.22+3.11$ & 0.15 \\
\hline A.Hpertension & $35(7046)$ & $37(74 \% 6)$ & 0.85 \\
\hline 5. Diabeles mellitus & $28(5696)$ & $26(5290)$ & 0.89 \\
\hline 6. Dyslipridumia & $33(66 \%)$ & $25(5040)$ & 0.16 \\
\hline 7. Fjection Fraction & 43-9496 & $33-7596$ & 0.67 \\
\hline \multicolumn{4}{|l|}{ 8. Angiographic chagnosis } \\
\hline Normal & $14(2896)$ & $7(14 \%)$ & \\
\hline Single vosed discase & $18(3696)$ & $20(4096)$ & \\
\hline Double vossd discase & $11(2296)$ & $16(3296)$ & \\
\hline Tripple vased discase & $9(18 \%)$ & $7(1496)$ & 0.41 \\
\hline
\end{tabular}

Table II: Development of contrast induced nephropathy (ICIN)

\begin{tabular}{llll}
\hline & $\begin{array}{c}\text { Group A } \\
\mathrm{s}=50\end{array}$ & $\begin{array}{c}\text { Group B } \\
\mathrm{s}=50\end{array}$ & p value \\
\hline Normal & $\begin{array}{l}40(80 \%) \\
\text { CIN developed }\end{array}$ & $\begin{array}{l}49(98 \%) \\
0(0 \%)\end{array}$ & 0.005 \\
\hline
\end{tabular}

Patients outcome as development of $\mathrm{CIN}$ are presented in table II.Among the patients in Group A who could not be given any premedication, $10 \%$ developed CIN but in Group $\mathrm{B}$ patient who who were given $\mathrm{N}$ acetyl cysteine and hydration as premedication, the incidence of CIN was found to be nil. ('p' value $=0.005$ ) .

\section{Discussion}

The antioxidant $\mathrm{N}$ acetyl cysteine was found to prevent $\mathrm{CIN}$ in patients undergoing coronary angiography with or without intervention in our study. CIN results from both renal tubular toxicity and renal medullary ischemia ${ }^{6}$. Exposure to contrast produces nephrotoxic oxygen free radicles. In addition to scavenging oxygen free radicles that mediate cell necrosis, $\mathrm{N}$ acetylcysteine may act as anti oxidant to inhibit ischemic cell death in the kidney ${ }^{7}$. Previous studies also suggest that $\mathrm{N}$ acetyl cysteine has vasodilator properties 10,11 . So $\mathrm{N}$ acetyl cysteine prevents $\mathrm{CIN}$ by inhibigting direct oxidative damage and by improving renal hemodynamics the incidence of CIN in our study is $20 \%$ in no premedication group and none of the patients of premedication group develop CIN group which is statistically significant. Although some of the patients serum creatinine of premedication group increased followinf contrast exposure, that was not sufficient to label them as CIN.Our findings of ioncidence of $\mathrm{CIN}$ is consistent with prevoius investigators findings ${ }^{12}$.

\section{Study Limitations}

Our limitation was -number of the study population was smaller, single center study and other causes of alternative etiology of nephropathy could not be excluded.

\section{Conclusion}

$\mathrm{N}$ Acetylcysteine along with hydaration prevents contrast induced nephropathy in high risk patients.

\section{References}

1. Werner C,Mann D, D'Elia J, Silva P.Effect of Saline, Mannitol and furosemide to prevent acute decrease in renal function induced by radiocontrast agents. NEJM.1994; 331:1416-20.

2. MCCollough P,Wolyn R,Rocher LL,Levin RN.Acute renal failure after coronary intervention.Am J Med. 1997;103 : $368-75$. 
3. Levy EM,Viscoli CM,Horwitz RI.The effect of acute renal failure on mortality.JAMA.1996;275:1489-94.

4. Cochran ST,Wong WS, Roe DJ.Predicting angiography induced acute renal function impairment.AJR.1983;141:1027-33.

5. Davison C,Matky M,Morris K et al.Cardiovascular and renal tyoxicity of a nonionic radiographic contrast agent after cardiac catheterization; a prospective trial.Ann Intern Med.1989;110:119-24.

6. Barrett B.Contrast nephrotoxicity.J Am Soc Nephrol.1994;5:125-37.

7. DiMari J,Megyesi J,Udvarhelyi N,Price P,Davis R,.N acetylcysteine ameliorates ischemic renal failure. $\mathrm{Am} J$ Physiol.1997;272:F292-F98.

8. Baliga R,Ueda N,Walker P,Shah Sv.Oxidant mechanisms in toxic renal failure.Am J Kidney Dis.1997;29:465-77.

9. Barkis GL, Lass N, Gaber AO,Jones JD, Burnett JC Jr. Radiocontrast medium-induced decline in renal function: a role for oxygen free radicles. Am J Physiol.1990;258:F115F20.

10. Jones A, Haynes W, Macgilchrist AJ, et al.N acetylcysteine(NAC) is a potent peripheral vasodilator.Gut 1994;35(suppl5):s10.

11. Zhang H, Spapen H,Nguen DN,Rogiers P, Baker J,Vincent JL.Effects of Nacetylcysteine on regional blood flow during endotoxic shock.EUR Surg Res. 1995;27:292-300.

12. Rasuli P,Hammond D,Metformin and contrast media.Can Assoc Radiol J 1998;49:161-66. 